\title{
Ameliorating the crossbred (Local $x$ Holstein Friesian) growing calves' growth performance, fecal microbial loads, and nutrient digestibility upon feeding local herbal feed additives as supplements
}

\author{
A. B. M. R. Bostami ${ }^{*}$, C. J. Yang ${ }^{2}$, M. R. I. Khan ${ }^{3}$, A. K. M. Z. Rabbi ${ }^{4}$, M. D. Hossain ${ }^{1}$, M. R. \\ Islam ${ }^{1}$, S. Ahmed ${ }^{5}$, M. Khairunnesa ${ }^{5}$, M. U. Habiba ${ }^{5}$ and S. M. M. Rahaman ${ }^{6}$
}

1Department of Animal Science and Nutrition, Faculty of Veterinary Medicine and Animal Science, Bangabandhu Sheikh Mujibur Rahman Agricultural University (BSMRAU), Gazipur-1706, Bangladesh.

2Department of Animal Science and Technology, Sunchon National University, Republic of Korea.

${ }^{3}$ Department of Animal Science, Faculty of Animal Husbandry, Bangladesh Agricultural University, Mymensingh-2202, Bangladesh.

${ }^{4}$ Faculty of Life Science and Natural Resources, Sunchon National University, Republic of Korea.

${ }^{5}$ Department of Dairy and Poultry Science, Faculty of Veterinary Medicine and Animal Science, Bangabandhu Sheikh Mujibur Rahman Agricultural University (BSMRAU), Gazipur-1706, Bangladesh.

${ }^{6}$ Department of Medicine, Faculty of Veterinary Medicine and Animal Science, Bangabandhu Sheikh Mujibur Rahman Agricultural University (BSMRAU), Gazipur-1706, Bangladesh.

*Corresponding author. Emails: rubayet@bsmrau.edu.bd, rubayetbau@gmail.com, rubayetbau@yahoo.co.in

Copyright $@ 2021$ Bostami et al. This article remains permanently open access under the terms of the Creative Commons Attribution License 4.0, which permits unrestricted use, distribution, and reproduction in any medium, provided the original work is properly cited.

Received 31st March, 2021; Accepted 19th April, 2021

\begin{abstract}
There is a growing interest to researchers in human and animal studies through the addition of medicinal plants or their derivatives to their feeds due to the presence of bioactive compounds. A study was carried out to monitor growth performance, fecal microbial loads and nutrient digestibility in crossbred (Local x Holstein Friesian) growing calves. Treatment groups were: HFA1 (CON: Control group, basal diet: green grass + concentrate), HFA2 (CON + fruit of Emblica officinalis Gaertn. $0.5 \%$ in-feed and $0.1 \%$ in-water), HFA3 (CON + fruit of Terminalia bellirica Gaertn. Roxb. 0.5\% in-feed and $0.1 \%$ in-water), and HFA4 (CON + fruit of Terminalia chebula Retz. $0.5 \%$ in-feed and $0.1 \%$ in-water). Addition of local herbal feed additives (HFA2, HFA3 and HFA4) improved weight gain and gain to feed ratio $(p<0.05)$. Fecal microbiological study indicated that, fecal pathogenic E. coli was suppressed, however, Lactobacilli $s p$. and their ratio was elevated in HFA2, HFA3 and HFA4 relative to HFA1 $(p<0.05)$. Digestibility of DM was upgraded whereas digestibility of CP was downtrended in herbal treated group as compared to control group $(\mathrm{p}<0.05)$. Thus, utilization of local herbal feed additives in the diet (in-feed and in-water) of crossbred growing calves might be evocative for promoting the growth performance rather than utilizing synthetic growth promoters.
\end{abstract}

Keywords: Fecal microbial loads, growth performance, herbal feed additives, nutrient digestibility.

\section{INTRODUCTION}

Feeding antibiotics, anabolic steroids and synthetic growth promoters is one of the technologies that have long been used to promote growth and milk production in livestock and poultry farming (Hardy, 2002). But recently, general resistance against the use of such synthetic chemical products has been growing among the people due to 
several reasons, such as harmful residual effects of antibiotic on human health. European parliament restricted the use of antibiotic in animal feeds in the European Union from January, 2006 (Official Journal of the European Union, 2003). Consequently, animal scientists are searching alternative additives for better feed efficiency and animal productivity by enhancing its metabolism and manipulating gastrointestinal tract function in both ruminant and non- ruminant (Greathead, 2003; Kamruzzaman et al., 2011). In animal Industry, various natural plants and their extracts have received much attention as most promising alternatives to growth promoters and antibiotics in the last decade (Bodas et al., 2008; Busquet et al., 2010; Cardozo et al., 2004).

There is a wide variety of natural sources which are capable to utilize in the livestock and poultry nutrition compromising the safety aspects of human health. Exploration of bioactive phytochemicals as natural feed additives is important aspects for both livestock and poultry production. Emblica officinalis (Gaertn.) is very copious in vitamin $\mathrm{C}$ and contains many minerals and vitamins such as calcium, iron, phosphorus, vitamin B complex and carotene; possess chemo-preventive, radiomodulatory, chemo-modulatory effects, free radical scavenging, antioxidant, anti-mutagenic, antiinflammatory and immune-modulatory properties that are efficacious for the preventive measures of cancer (Baliga and Dsouza, 2011). It was reported that, E. officinalis was effective in case of sheep on the aspect of productive performance and diarrhea prevention activity due to presence of bioactive compounds (Bostami et al., 2015b). Terminalia bellirica (Gaertn.) helps in preventing disease, bestow longevity, improve intellectual prowess and strength and aids in mental refreshment (Pal and Jain, 1989). Terminalia chebula Retz. composed of chebulinic acid, ellagic acid, tannic acid, 2,4-chebulyl- $\beta$-Dglucopyranose, chebulinic acid and some other phytochemicals, used as purported antitussive, homeostatic, cardiotonic, laxative and diuretic (Saleem et al., 2002; Tewari et al., 2017).

There are several researches in broiler and pig on performance and meat quality aspects fed with herbal feed additives having phytochemicals, however, very few researches have been conducted in case of ruminants due to complex digestive system and wide variety of sources (Valenzuela-Grijalva et al., 2017). Therefore, it is urge to conduct more study in case of ruminant animal's performance and meat quality supplemented with herbal feed additives for conclusive findings. Therefore, an attention was grown on the local herbal feed additives that can be used in the diet of crossbred growing cattle.

It was hypothesized that, herbal feed additives (prepared from the traditional medicinal plants) composed of bioactive compounds or phytochemicals are able to function in the physiology of nutrition of animal, might have positive effect on growth performance, nutrient digestibility and fecal microbial loads. In addition, in the present situation, there is insufficient scientific research in case of ruminant animal on locally available herbal feed additive sources. It is hankering for the ample of research data and need to clarify whether local herbal feed additives enhance feedstuff digestion and promote growth or not in Bangladesh or Indian sub-continent context. Emblica officinalis Gaertn. or Phyllanthus emblica Linn. Euphorbeaceae), (amla), Terminalia bellirica (Gaertn.) Roxb. (bahera) and Terminalia chebula Retz. (Combretaceae) (haritaki) are commonly used in Bangladesh as well as in the other part of the world, where most of the researches are focused on human pharmacological aspects. Therefore, the present investigation was undertaken with an objective of to monitor growth response, nutrient digestibility, dimension of fecal microbial loads in crossbred (Local x Holstein Friesian) growing calves.

\section{MATERIALS AND METHODS}

\section{Preparation, processing and analysis of samples}

The whole fruit of Emblica officinalis Gaertn. (amla), Terminalia bellirica (Gaertn.) Roxb. (bahera) and Terminalia chebula Retz. (haritaki) was collected from local market and BSMRAU of Gazipur, Bangladesh. After collection of the samples, they were dried at $60^{\circ} \mathrm{C}$, ground and stored in air tight container in room temperature. Following processing, the fruit of Emblica officinalis Gaertn. (amla), Terminalia bellirica (Gaertn.) Roxb. (bahera) and Terminalia chebula Retz. (haritaki) was added separately in the treatment group. The pharmacological aspects are already proved and wellknown fact in different human studies; therefore, details are not mentioned in this study. Proximate analyses (DM: Dry matter, CP: Crude protein, CF: Crude fiber, NFE: Nitrogen free extract, EE: Ether extract and ash) of roughage, concentrate and herbal feed additives were carried out for each sample in triplicate by following the method of AOAC (1990). The proximate composition of concentrate diet was shown in Table 1.

\section{Experimental design, animals and diets}

Present research on medicinal plant utilization as herbal feed additives in case of crossbred (Local $x$ Holstein Friesian) growing calves was conducted at Livestock and Poultry Farm under the Faculty of Veterinary Medicine and Animal Science, Bangabandhu Sheikh Mujibur Rahman Agricultural University (BSMRAU), Gazipur-1706, Bangladesh. The feeding trial was conducted for a period of 90 days. Animals were provided general feeding with roughage, concentrate and fresh water for 7 days as adjustment period. A completely randomized design was followed for the allocation of the experimental animals. 
Table 1. Feed ingredients of experimental diet provided to crossbred (Local x Holstein Friesian) growing calves.

\begin{tabular}{lc}
\hline Ingredients & $\begin{array}{c}\text { Percentage as fed- } \\
\text { basis }(\%)\end{array}$ \\
\hline Corn, ground & 22.37 \\
Wheat bran & 15.00 \\
Wheat, ground & 15.00 \\
Rice bran & 10.00 \\
Cotton seed meal & 7.00 \\
Corn gluten meal & 4.50 \\
Protein concentrate & 9.90 \\
Sunflower meal & 2.50 \\
Soybean meal & 2.76 \\
Rapeseed meal & 1.00 \\
Distillers dried grains & 1.00 \\
Molasses & 5.00 \\
Salt & 0.60 \\
Limestone (1 mm) & 1.87 \\
Di calcium phosphate (DCP) & 0.50 \\
Calcium sulfate & 0.30 \\
Mineral premix & 0.35 \\
Vitamin premix & 0.35 \\
& \\
Chemical composition & \\
Moisture & 12.29 \\
Crude ash & 6.10 \\
Crude fat & 2.57 \\
Crude fiber & 5.71 \\
Crude protein & 14.74 \\
NFE & 58.71 \\
\hline
\end{tabular}

Twelve animals of almost similar age (about six months, based on records of LPF, BSMRAU), average body weight $(51 \pm 1.0 \mathrm{~kg})$ was selected and allocated randomly to four treatment groups (with or without herbal feed additives) having three calves in each group.

One group was provided with roughage (chopped straw and green grass) and concentrates feed without any medicinal plant as feed additives considered as control group. Another group was provided the medicinal plants as feed additives with roughage and concentrates feed and treated as treatment group. Dietary treatment groups were: HFA1 (CON: Control group, basal diet: roughage + concentrate), HFA2 (CON + fruit of Emblica officinalis Gaertn. $0.5 \%$ in-feed and $0.1 \%$ in-water), HFA3 (CON + fruit of Terminalia bellirica Gaertn. Roxb. 0.5\% in-feed and $0.1 \%$ in-water), and HFA4 (CON+ fruit of Terminalia chebula Retz. $0.5 \%$ in-feed and $0.1 \%$ in-water). Herbal feed additives were added to the concentrate diet at the level of $0.5 \%$ and with drinking water at the level of $0.1 \%$. All the animals were reared according to the animal care and management committee and ethical committee of Bangabandhu Sheikh Mujibur Rahman Agricultural
University, Gazipur-1706, and followed the guidelines and suggestions of directorate of livestock services, Peoples Republic of Bangladesh.

\section{Management and monitoring of animals}

The experiment was conducted in cattle shed containing separated pens and each pen was fully equipped with a feeding and watering trough as required for growing calves. The calves were randomly allocated to the pens of the same house with similar environment. The allocated space was fixed to $8.5 \mathrm{~m}^{2} /$ pen. Chopped straw, green grass and concentrate was provided in each pen four times a day, where sand was used as bedding material and the house was equipped with a good ventilation facility. Sufficient lighting and aeration facility, regular cleaning of pens was confirmed by skilled labour. Since the average body weight of the animals were $51 \pm 1.0 \mathrm{~kg}$, an average 5 to $7 \mathrm{~kg}$ of roughage and 1.5 to $1.7 \mathrm{~kg}$ of concentrate feed was supplied to each growing animal. Fresh clean drinking water was provided ad libitum. Given amount of roughage and concentrate, the amount of refusal was measured separately and total intake was recorded daily. Animal excreta were removed daily, and each pen was cleaned regularly; temperature and humidity in the calf house was monitored regularly. All calves were weighed monthly throughout the experimental period. Fecal samples were collected from each group on the last week of the trial and the samples were further analyzed in the Laboratory of Faculty of Veterinary Medicine and Animal Science, BSMRAU, Gazipur-1706, Bangladesh. After feeding trial, the fecal analysis was conducted, the nutrient digestibility was estimated following the standard procedure. The duration of the experiment was one year for feeding trial and other analysis.

\section{Estimation of digestibility of nutrients}

The digestibility coefficients were measured from fecal samples taken directly from the rectum of the animals. The samples were collected from the seventh to the tenth day of experimental period. The time of sample collection was fixed according to the following distribution: 7th day (6 a.m. and 2 p.m.); 8th day (8 a.m. and 4 p.m.); 9th day (10 a.m. and 6 p.m.); and 10 th day (12 p.m. and 8 p.m.). After the samples collection, the feces samples were dried in oven $\left(60^{\circ} \mathrm{C} / 72\right.$ hours $)$ and processed in a Wiley mill $(1-\mathrm{mm})$. The digestibility coefficients were measured following the methodology applied by Lazzarini et al. (2009).

\section{Collection and analysis of fecal samples}

For microbial analysis, growing crossbred calves were randomly selected from each pen and identified by ear tag. 
Table 2. Proximate composition of experimental herbal feed additives provided with basal diet to crossbred (Local $x$ Holstein Friesian) growing calves.

\begin{tabular}{lccc}
\hline Parameters & Emblica officinalis & Terminalia bellirica & Terminalia chebula \\
\hline \% DM (air dry basis) & 94.34 & 95.52 & 92.33 \\
CP (\% as DM basis) & 5.45 & 7.72 & 3.45 \\
CF (\% as DM basis) & 9.05 & 8.85 & 10.35 \\
NFE (\% as DM basis) & 77.83 & 77.75 & 81.05 \\
EE (\% as DM basis) & 1.42 & 1.27 & 1.25 \\
Ash (\% as DM basis) & 6.92 & 4.92 & 4.42 \\
\hline
\end{tabular}

DM: Dry matter, CP: Crude protein, CF: Crude fiber, NFE: Nitrogen free extract, EE: Ether extract.

Table 3. Growth performance of crossbred (Local x Holstein Friesian) growing calves supplemented with herbal feed additives.

\begin{tabular}{|c|c|c|c|c|c|c|}
\hline Growth performance & HFA1 & HFA2 & HFA3 & HFA4 & SEM & P-value \\
\hline ILW (kg/calf) & 51.27 & 51.20 & 51.03 & 51.30 & 0.105 & 0.386 \\
\hline FLW (kg/calf) & $69.03 b$ & $74.77 a$ & $76.33 a$ & $74.60 \mathrm{a}$ & 0.550 & 0.000 \\
\hline WG (kg/calf) & $17.77 b$ & $23.57 a$ & $25.30 a$ & 23.30a & 0.591 & 0.000 \\
\hline $\mathrm{FI}(\mathrm{kg} / \mathrm{d})$ & 134.93 & 139.63 & 140.17 & 140.59 & 2.318 & 0.358 \\
\hline FE (gain/feed) & $0.13 b$ & $0.17 \mathrm{a}$ & $0.18 a$ & $0.17 \mathrm{a}$ & 0.005 & 0.002 \\
\hline
\end{tabular}

$a, b, c$ Means in the same row with different superscripts are significantly different $(p<0.05)$. Dietary treatment groups: HFA1 (CON: Control group, basal diet: green grass + concentrate), HFA2 (CON+ fruit of Emblica officinalis Gaertn. $0.5 \%$ in-feed and $0.1 \%$ in-water), HFA3 (CON + fruit of Terminalia bellirica Gaertn. Roxb. $0.5 \%$ in-feed and $0.1 \%$ in-water), and HFA4 (CON+ fruit of Terminalia chebula Retz. $0.5 \%$ in-feed and $0.1 \%$ in-water). ILW: Initial live weight, FLW: Final live weight; WG: Weight gain; FI: Feed intake; FE: Feed efficiency (gain to feed ratio).

On day 90 of the experimental period, fecal samples were collected directly from the rectum of the growing calves in sterile polyethylene bags in order to avoid any additional contamination of the samples. Serial dilutions of one gram of samples were then prepared by sterile saline solution $(0.9 \% \mathrm{NaCl})$ from $10^{-1}$ to $10^{-9}$ (10-fold) for further microbial analysis. The specific culture techniques were used for the microbial assay of fecal samples. The microbial groups analyzed were Lactobacillus spp. (de Man, Rogosa and Sharpe (MRS) agar, Difco'M), E. coli (MacConkey (MAC) agar, Difco ${ }^{\mathrm{TM}}$ ), Salmonella sp. (Salmonella-Shigella (SS) agar, Difco ${ }^{\mathrm{TM}}$ ), Streptococci sp. (Bile Esculin Azide Agar, Hardy Diagnostics), Compylobactor sp. (Campy Cefex agar, $\mathrm{BBL}^{\mathrm{TM}}$ ), total anaerobes (plate-count agar, anaerobic chamber, Neogen Food Safety), and total aerobes (platecount agar, Neogen Food Safety). Specific agar media was prepared following manufacturers guidelines for the growth of specific microorganisms. The specific agar plates were inoculated with three dilutions of fecal samples and each in duplicate, were prepared for incubation. After spreading the diluted samples, the agar plates were then incubated at $37^{\circ} \mathrm{C}$ for 24 to $48 \mathrm{~h}$, after which microbial colonies were immediately counted. Total microbial colony counts in the samples obtained from the fecal samples were measured by the plate-count technique explained by Wang et al. (2011). Microflora enumerations were expressed as log10 CFU per gram.

\section{Statistical analysis}

All data were subjected to ANOVA using the General
Linear Models (GLM) function of the Statistical Analysis System (SAS, 2003, Version 9.1, SAS Institute, Cary, NC, USA). Each experimental pen was considered as the experimental unit for growth performance and nutrient digestibility, whereas an individual crossbred animal was served as the experimental unit for fecal microbial loads analysis. A probability level of $p<0.05$ was considered as statistically significant and a level of $p<0.10$ was considered as a statistical tendency.

\section{RESULTS}

\section{Nutrient composition of the feed additives and growth response of crossbred (Local $x$ Holstein Friesian) growing calves fed different treatment diets}

The proximate composition of herbal feed additives was shown in Table 2. Terminalia bellirica composed of higher crude protein followed by Emblica officinalis and Terminalia chebula. Emblica officinalis contain higher ash content than that of Terminalia bellirica and Terminalia chebula. Where the crude fiber content was higher in Terminalia chebula followed by Emblica officinalis and Terminalia bellirica. Table 3 demonstrate the growth performance of crossbred (Local $x$ Holstein Friesian) growing calves as supplemented by with or without herbal feed additives. It was observed that, addition of herbal feed additives (HFA2, HFA3, HFA4) improves the final live weight, body weight gain and gain to feed ratio in the crossbred (Local $x$ Holstein Friesian) growing calves as compared to HFA1 $(p<0.05)$. In the herbal treated group 
Table 4. Fecal microbial loads (log10 CFU per gram) of crossbred (Local $x$ Holstein Friesian) growing calves supplemented with herbal feed additives.

\begin{tabular}{lllllll}
\hline Microbial loads & HFA1 & HFA2 & HFA3 & HFA4 & SEM & P-value \\
\hline Lactobacillus $s p$. & $6.25 \mathrm{~b}$ & $6.44 \mathrm{a}$ & $6.40 \mathrm{a}$ & $6.40 \mathrm{a}$ & 0.03 & 0.0031 \\
E. coli & $4.69 \mathrm{a}$ & $4.40 \mathrm{~b}$ & $4.50 \mathrm{~b}$ & $4.40 \mathrm{~b}$ & 0.06 & 0.0064 \\
Total aerobes & 6.58 & 6.60 & 6.57 & 6.58 & 0.03 & 0.9146 \\
Total anaerobes & 6.58 & 6.57 & 6.60 & 6.58 & 0.03 & 0.9146 \\
Lactobacilli: E. coli & $1.33 \mathrm{~b}$ & $1.47 \mathrm{a}$ & $1.42 \mathrm{a}$ & $1.46 \mathrm{a}$ & 0.02 & 0.0007 \\
Streptococci & 6.65 & 6.75 & 6.65 & 6.70 & 0.06 & 0.5567 \\
Compylobactor sp. & 6.70 & 6.75 & 6.74 & 6.78 & 0.08 & 0.9398 \\
\hline
\end{tabular}

a,b Means in the same row with different superscripts are significantly different $(p<0.05)$. HFA1 (CON: Control group, basal diet: green grass + concentrate), HFA2 (CON+ fruit of Emblica officinalis Gaertn. $0.5 \%$ in-feed and $0.1 \%$ in-water), HFA3 (CON + fruit of Terminalia bellirica Gaertn. Roxb. $0.5 \%$ in-feed and $0.1 \%$ in-water), and HFA4 (CON+ fruit of Terminalia chebula Retz. $0.5 \%$ in-feed and $0.1 \%$ in-water).

around 30 to $40 \%$ more growth was exhibited as compared to non-herbal treated group. However, feed intake was not affected after addition of herbal feed additives to the diet of crossbred growing calves ( $p>0.05)$.

\section{Fecal microbiota of crossbred (Local $x$ Holstein Friesian) growing calves fed different treatment diets}

Table 4 shows the fecal microbial loads in crossbred (Local $x$ Holstein Friesian) growing calves fed different treatment diets. There was observed suppression of pathogenic $E$. coli in the HFA2, HFA3 and HFA4 group compared to HFA1 group $(p<0.05)$; whereas elevation of beneficial microbes Lactobacillus $s p$. and ratio of Lactobacilli $s p$. to E. coli in the HFA2, HFA3 and HFA4 group in comparison to HFA1 group $(p<0.05)$.

\section{Digestibility of nutrients of crossbred (Local $x$ Holstein Friesian) growing calves fed different treatment diets}

Figure 1 depicts the effects of herbal feed additives on total tract digestibility of different nutrients in crossbred (Local $x$ Holstein Friesian) growing calves. It was exemplified that the DM digestibility was higher in HFA2, HFA3 and HFA4 as compared to HFA1 $(p<0.05)$. However, the digestibility of CP was lower in HFA2, HFA3 and HFA4 relative to that of HFA1 $(p<0.05)$.

\section{DISCUSSION}

\section{Growth response in crossbred growing calves}

From few decades, herbal feed additives have been attracted an increasing interest as an alternative feeding strategy to replace synthetic growth promoters (Kumar et al., 2014; Bostami et al., 2015a; Bostami et al., 2017) due to creating health hazard issues. The growthenhancing feed additives provide a beneficial impact on the ecosystem of gastrointestinal microbiota through controlling potential pathogens (Roth and Kirchgessner, 1998; Windisch et al., 2008a). Therefore, researches focused on both ruminants and non-ruminant animals. In the present experiment, the herbal feed additive fed groups showed better final live weight, weight gain and gain to feed ratio than that of without herbal feed additives group which was considered as control group.

In the current study herbal treated group exhibited 30 to $40 \%$ more weight gain as compared to without herbal group. Wang et al., (2011) reported that a better weight gain was exhibited by supplementing garlic (Allium sativum) in the diet of pigs. The results of the current study confirmed previous findings. It was elucidated (Sultana et al., 2012) that $27 \%$ more daily gain in native growing bull calf with the addition of herbal feed $S$. mukorossi in the diet using concentrate mixture supplement @ 1.0\% of the body weight of the animals in comparison to $0.5 \%$. Better weight gain and gain to feed ratio in the herbal feed additives treated group in the current study might be due to crude protein, ash and other proximate components influence on their efficiency of utilization in the ruminal digestion and microbial balance. Additionally, the presence of phytochemicals might be associated with higher growth performance in current study where available phyto-constitunets were ellagic acid, ellagitannin, gallic acid, chebulic acid, belleric acid present in the fruit of Emblica officinalis Gaertn., Terminalia bellirica Gaertn. Roxb. and Terminalia chebula Retz. (Combretaceae) in HFA2, HFA3 and HFA4 group.

Phytochemicals, essential oils and organic acids present in herbal feed additives can modulate the gut microbial environment and exhibit beneficial interactions (Valenzuela-Grijalva et al., 2017); consequently, being able to enhance the growth performance (Partanen and Mroz, 1999). During the critical phases of an animal's production cycle, balancing of gastrointestinal microbiota is important; because, animal expose less to toxins and other undesired metabolites generated from microbes due to higher stabilizing capability of intestinal health (Tekeli et al., 2007; Windisch et al., 2008b). Though the plant sources and the animal species were not similar, the non-significant effects of feeding herbal sources on feed intake of crossbred animal found in this study are in agreement with the results of previous studies (Abreu et 


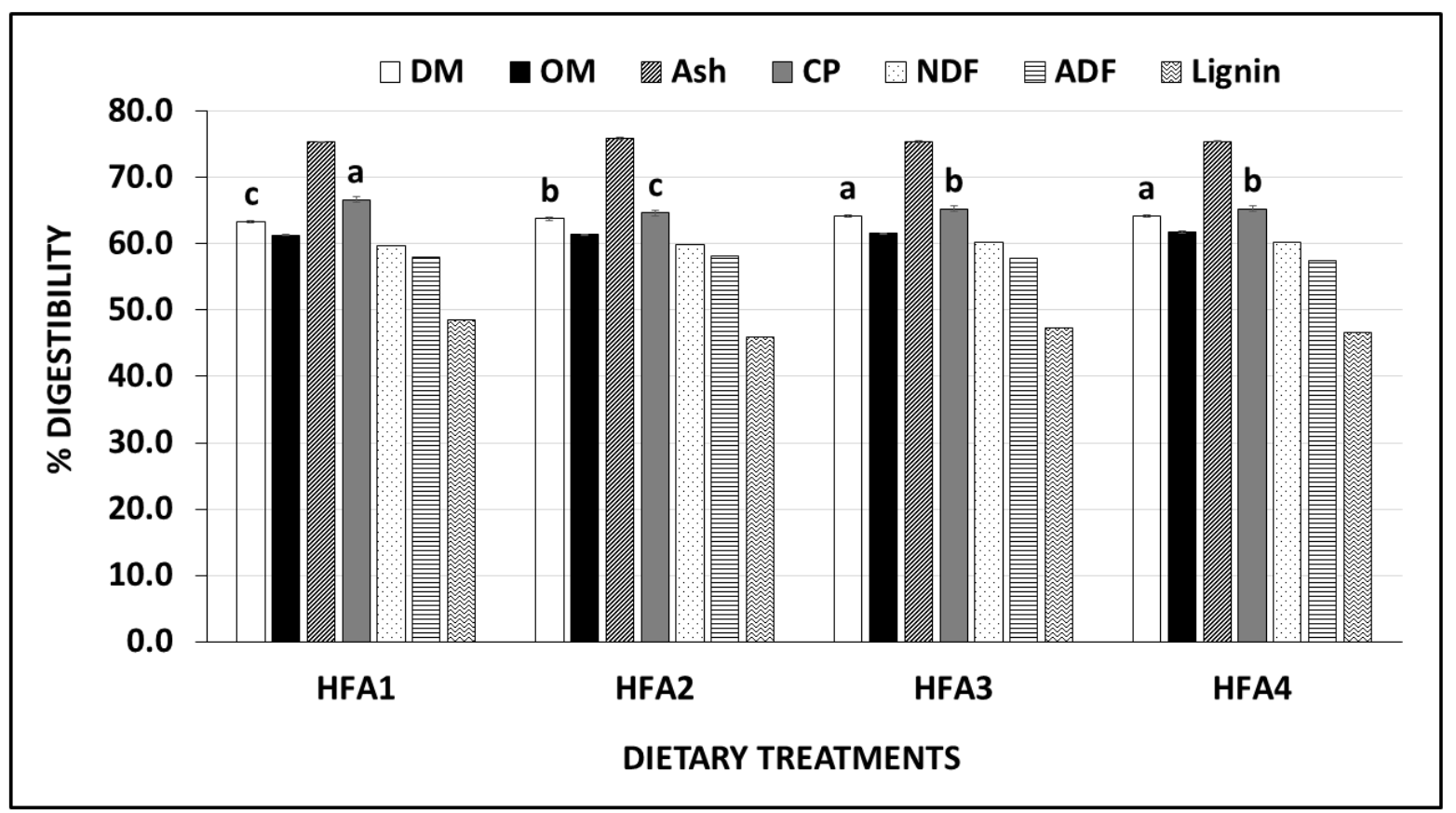

Figure 1. Nutrient digestibility (\%) of crossbred (Local x Holstein Friesian) growing calves supplemented with herbal feed additives. ${ }^{a, b, c}$ Means in the same bar with different letter are significantly different $(p<0.05)$. Dietary treatment groups: HFA1 (CON: Control group, basal diet: green grass + concentrate), HFA2 (CON+ fruit of Emblica officinalis Gaertn. 0.5\% in-feed and 0.1\% in-water), HFA3 (CON + fruit of Terminalia bellirica Gaertn. Roxb. $0.5 \%$ in-feed and $0.1 \%$ in-water), and HFA4 (CON+ fruit of Terminalia chebula Retz. 0.5\% in-feed and $0.1 \%$ in-water). DM: Dry matter, OM: Organic matter, CP: Crude protein, ADF: Acid detergent fiber, NDF: Neutral detergent fiber.

al., 2004; Ngamsaeng et al., 2006). Abreu et al. (2004) and Ngamsaeng et al. (2006) reported that supplementation of $S$. saponaria fruits in case of sheep not affected the feed intake however, it is beneficial to improve ruminal VFA profile and microbial efficiency. Abreu et al. (2004) and Ngamsaeng et al. (2006) stated that mangosteen peel (Garcinia mangostana) can be utilized as a dietary source which can slightly affect the feed intake but are efficient for the manipulation of rumen ecology resulting in improvement of rumen fermentation and productivity potential in case of cattle.

\section{Fecal microbiota in crossbred growing calves}

The developing antibiotic resistance of several bacterial strains such as Streptococci, E. coli, Campylobacter and Enterococci (Aarestrup et al., 2002) and decreased growth performance in animals are noticed after antibiotic feed withdrawal period. So, there is a rising concerns about finding a good alternative to synthetic growth promoters. Herbal treated crossbred growing calves showed suppression of pathogenic E. coli whereas elevation of beneficial microbes Lactobacillus $s p$. and ratio of Lactobacilli sp. to E. coli in the fecal samples in the current study. In support of the current study, reduction of $E$. coli was found by Wang et al. (2011) in pig study through feeding garlic which is composed of bioactive compounds. Diaz et al. (1993) in a study of mature tropical crossbred sheep demonstrated that, Sapindus saponaria able to decrease the protozoal population and increase the total viable bacteria, cellulolytic bacteria and fungi with the dose of $50 \mathrm{~g}$ of $S$. saponaria compared to $0 \mathrm{~g}$ of $S$. saponaria. The reduction of E. coli and elevation of Lactobacillus $s p$. in the present study might be due to the different mode of action of plant secondary metabolites present in the fruits of $E$. officinalis, $T$. chebula and T. bellirica used as herbal feed additives.

The medicinal plants $E$. officinalis, $T$. chebula and $T$. bellirica used in the HFA2, HFA3 and HFA4 groups contain phytochemicals which can influence selectively the microorganisms by an anti-microbial activity or by a favorable stimulation of the eubiosis of the microflora. Herbal plants contain essential oils which possess the strongest antibacterial properties against pathogens because of the presence of high percentage of phenolic compounds. The phenolic compounds include carvacrol, eugenol (2-methoxy-4-(2-propenyl) phenol and thymol (Dorman and Deans, 2000; Lambert et al., 2001), which additionally can induce inhibition of extracellular enzyme secretion to prevent the negative impact of microbes (Gill and Holley, 2006). E. officinalis, T. bellirica and T. chebula 
phenolic compounds might be able to dismantle the bacterial outer membrane, discharging the lipopolysaccharides and uplifting the permissibility of the cytoplasmic membrane to adenosine triphosphate (ATP) (organic compound providing energy to regulate biological processes into the cell) and assemblage the cytoplasmic membrane (Epand et al., 2010; Helander et al., 1998). Therefore, the phenolic compounds present in the $E$. officinalis, $T$. bellirica and $T$. chebula might be attributable to the diminishing of $E$. coli through anti-microbial activity, and up-gradation of Lactobacilli sp. and ratio of Lactobacilli $s p$. to $E$. coli through favorable stimulation of the eubiosis of the microflora and gut microbial balance.

Consistently, it was stated that, Terminalia chebula RETZ. composed of two potent antimicrobial substances (gallic acid and its ethyl ester) which acts against Staphylococcus aureus, a methicillin-resistant strains (Sato et al., 1997). Similarly, E. officinalis, T. bellirica and $T$. chebula also contain flavonoids and organic acids, gallic acid, ethyl gallate (Lee et al., 2010; Saleem et al., 2002), terflavin A, punicalagin, luteolin, tannic acid, terchebin, chebulic acid, phenolic acid compound and luteic acid, which exhibit antimicrobial activity resulting in suppression of pathogenic microbes and ameliorating the beneficial microbes (Saxena et al., 2013). Thus, current research finding supported the previous statement, because it revealed the suppression of pathogenic microbes; and elevation of the beneficial microbes and the ratio of beneficial to pathogenic microorganisms. The other reason of reduction of fecal microbiota with the herbal feed additives treated groups of the current study might be due to the hydrophobic nature of herbal plant extracts. Where hydrophobicity is an important characteristic of essential oils or the components that are generated from the medicinal plants, which are usually utilized as herbal feed additives (Vergis et al., 2015). Such types of nature of medicinal plant enables them to make a lipids segregation in the bacterial cell wall and mitochondria, muddles to make structures grasping more accessible (Joshi et al., 2011).

\section{Nutrient digestibility in crossbred growing calves}

The digestibility of feed materials in livestock and poultry is important parameter for indicating better feed efficiency and productivity. Ando et al. (2003) stated that, the addition of peppermint in the diet of cattle able to increase nutrient digestibility, decrease the ammonia-nitrogen concentration and protozoal population, and manipulate the rumen fermentation. It was reported that, ruminal DM and OM digestibility can increase (Yang et al., 2007; Yang et al., 2015) after feeding garlic oil to dairy cattle. In another research, it was reported that garlic powder supplementation can increase the in vitro true digestibility (Kongmun et al., 2010). It was stated that treatment with essential oils in the diet able to improve the dry matter and nitrogen digestibility than that of untreated control diets (Cho et al.,
2005; Zhang et al., 2012). Consistent to these findings, it was observed that addition of local herbal feed additives improved the digestibility of dry matter as compared nonherbal group. Inconsistently, Busquet et al. (2005) reported that DM, OM, NDF and ADF true digestibility were not affected by addition of garlic oil. Plant extracts or bioactive constituents can modulate the rumen microbial environment, fermentation pattern and microbial activity which consequently can influence the digestibility of nutrients (Hart et al., 2008).

In the present findings, a decrement was depicted in the apparent digestibility of $\mathrm{CP}$ in the herbal feed additives group inoculated animals (HFA2, HFA3 and HFA4) compared to non-herbal group (HFA1) which was in agreement with previous observations. Wanapat et al. (2008) reported that lemongrass or garlic powder supplementations can decrease CP digestibility. A tendency of decrease in CP digestibility was reported by Wanapat et al. (2013) by adding herb in beef cattle. Digestibility pattern of CP can be affected by the availability of highly degradable nitrogenous compound (Lazzarini et al., 2009), where the amount of highly degradable nitrogenous compound can be associated with the rumen microbial population and action influenced by the plant secondary metabolites (Kamra et al., 2008; Patra and Saxena, 2009). Cynodon nlemfuensis supplemented with Gliricidia sepium can be added to the diet of sheep since it is able to supply highly degradable $\mathrm{N}$ to the rumen and appears to elevate the microbial $\mathrm{N}$ supply to the small intestine (Alayon et al., 1998). Phytochemicals generated by medicinal plants affect the rumen microbial populations together with fermentation which consequently will permit a better management of the rumen ecosystem and sway the digestibility of nutrients (Kamra et al., 2008).

However, the positive result of the present study may have been caused by secondary plants metabolites: flavonoid, isoflavons, ellagitannins, emblicanin B, emblicanin, pedunculagin, punicafolin, phyllanemblinin $A$, A punigluconin, phyllanemblin, polyphenols, kaempferol, flavonoids, ellagic acid and gallic acid substances generated from the fruit of $T$. bellirica, E. officinalis and $T$. chebula. Such types of bioactive compounds are potential to positively affecting the intestinal microbial balance and villus height (Sehm et al., 2007; Zhang et al., 2012), consequently able to influence the digestion, metabolism and absorption process (Jobgen et al., 2006). The most notable intrinsic effects of herbal plant extracts are their antimicrobial activity. The clear in vitro evidence of the antibacterial, antiviral and antifungal activity of many plant extracts against animals and/or foodborne pathogens has been reported in the various scientific literature (Dorman and Deans, 2000; Rota et al., 2004).

\section{Conclusion}

The result revealed that the fruit of Emblica officinalis Gaertn., Roxb., Terminalia bellirica, Gaertn. and 
Terminalia chebula Retz. as herbal feed additives at the level of $0.5 \%$ in-feed and $0.1 \%$ in-water promoted growth performance (weight gain and gain to feed ratio) and influence nutrient digestibility (DM was upgraded and CP was down-trended) in crossbred (Local x Holstein Friesian) growing calves. While the fecal pathogenic microbial colony of $E$. coli was suppressed, and the beneficial microbial colony of Lactobacilli sp. and their ratio was elevated. Thus, utilization of local medicinal plants as herbal feed additives in the diet of crossbred (Local $x$ Holstein Friesian) growing calves might be suggestive for growth promotion instead of utilizing synthetic growth promoters that are available in the market.

\section{ACKNOWLEDGEMENT}

Authors wish to express gratitude to Research and Management Committee of Bangabandhu Sheikh Mujibur Rahman Agricultural University, Gazipur-1706, Bangladesh and Ministry of Science and Technology, Bangladesh for financial and technical support aided in the practical knowledge and experience.

\section{CONFLICT OF INTEREST}

Authors declare no conflict of interest regarding this research and publications.

\section{REFERENCES}

Aarestrup, F. M., Hasman, H., Jensen, L. B., Moreno, M., Herrero, I. A., Domínguez, L., Finn, M., \& Franklin, A. (2002). Antimicrobial resistance among Enterococci from Pigs in three European countries. Applied and Environmental Microbiology, 68(8), 4127-4129.

Abreu, A., Carulla, J. E., Lascano, C. E., Díaz, T. E., Kreuzer, M., \& Hess, H. D. (2004). Effects of Sapindus saponaria fruits on ruminal fermentation and duodenal nitrogen flow of sheep fed a tropical grass diet with and without legume. Journal of Animal Science, 82(5), 1392-1400.

Alayon, J. A., Ramirez-Aviles, L., \& Ku-Vera, J. C. (1998). Intake, rumen digestion, digestibility and microbial nitrogen supply in sheep fed Cynodon nlemfuensis supplemented with Gliricidia sepium. Agroforestry Systems, 41(2), 115-126.

Ando, S., Nishida, T., Ishida, M., Hosoda, K., \& Bayaru, E. (2003). Effect of peppermint feeding on the digestibility, ruminal fermentation and protozoa. Livestock Production Science, 82(2-3), 245-248.

AOAC (1990). Official Methods of Analysis. Association of Official Analytical Chemistry (15 Ed), Washington, D.C., U.S.A.

Baliga, M. S., \& Dsouza, J. J. (2011). Amla (Emblica officinalis Gaertn), a wonder berry in the treatment and prevention of cancer. European Journal of Cancer Prevention, 20(3), 225239.

Bodas, R., López, S., \& Fernandez, M. (2008). In vitro screening of the potential of numerous plant species as antimethanogenic feed additives for ruminants. Animal Feed Science and Technology, 145(1-4), 245-258.
Bostami, A. B. M. R., Ahmed, S. T., Islam, M. M., Mun, H. S., Ko, S., Kim, S., \& Yang, C. J. (2015a). Growth performance, fecal noxious gas emission and economic efficacy in broilers fed fermented pomegranate byproducts as residue of fruit industry. International Journal of Advanced Research, 3(3), 102-114.

Bostami, A. B. M. R., Selim, A. S. M., Hoque, S. A. M., Rabbi, A. K. M. Z., \& Siddiqui, M. N. (2015b). Effects of medicinal herb (Emblica officinalis) on growth performance, fecal microbiota and diarrhea prevalence in growing sheep. International Journal of Current Research, 7(3), 13720-13727.

Bostami, A. B. M. R., Sarker, M. S. K., \& Yang, C. J. (2017). Performance and meat fatty acid profile in mixed sex broilers fed diet supplemented with fermented medicinal plant combinations. Journal of Animal and Plant Sciences, 27(2), 360-372.

Busquet, M., Calsamiglia, S., Ferret, A., Carro, M. D., \& Kamel, C. (2005). Effect of garlic oil and four of its compounds on rumen microbial fermentation. Journal of Dairy Science, 88(12), 4393-4404.

Busquet, M., Calsamiglia, S., Ferret, A., Carro, M. D., \& Kamel, C. (2010). Effect of garlic oil and four of its compounds on rumen microbial fermentation. Journal of Dairy Science, 88(12), 4393-4404.

Cardozo, P. W., Calsamiglia, S., Ferret, A., \& Kamel, C. (2004). Effects of natural plant extracts on ruminal protein degradation and fermentation profiles in continuous culture 1. Journal of Animal Science, 82(11), 3230-3236.

Cho, J. H., Chen, Y. J., Min, B. J., Kim, H. J., Kwon, O. S., Shon, K. S., Kim, I. H., Kim, S. J., \& Asamer, A. (2005). Effects of essential oils supplementation on growth performance, IgG concentration and fecal noxious gas concentration of weaned pigs. Asian-Australasian Journal of Animal Sciences, 19(1), 80-85.

Diaz, A., Avendano, M., \& Escobar, A. (1993). Evaluation of Sapindus saponaria as a defaunating agent and its effects on different ruminal digestion parameters. Research for Rural Development, 5(2), 1-6.

Dorman, H. J. D., \& Deans, S. G. (2000). Antimicrobial agents from plants: antibacterial activity of plant volatile oils. Journal of Applied Microbiology, 88(2), 308-316.

Epand, R. F., Pollard, J. E., Wright, J. O., Savage, P. B., \& Epand, R. M. (2010). Depolarization, bacterial membrane composition, and the antimicrobial action of ceragenins. Antimicrobial Agents and Chemotherapy, 54(9), 3708-3713.

Gill, A. O., \& Holley, R. A. (2006). Inhibition of membrane bound ATPases of Escherichia coli and Listeria monocytogenes by plant oil aromatics. International Journal of Food Microbiology, 111(2), 170-174.

Greathead, H. (2003). Plants and plant extracts for improving animal productivity. Proceedings of the Nutrition Society, 62(02), 279-290.

Hardy, B. (2002). The issue of antibiotic use in the livestock industry: What have we learned? Animal Biotechnology, 13(1), 129-147.

Hart, K. J., Yáñez-Ruiz, D. R., Duval, S. M., McEwan, N. R., \& Newbold, C. J. (2008). Plant extracts to manipulate rumen fermentation. Animal Feed Science and Technology, 147(1-3), 8-35.

Helander, I. M., Alakomi, H.-L., Latva-Kala, K., Mattila-Sandholm, T., Pol, I., Smid, E. J., Gorris, L. G. M., \& von Wright, A. (1998). Characterization of the action of selected essential oil components on gram-negative bacteria. Journal of Agricultural and Food Chemistry, 46(9), 3590-3595.

Joshi, B., Prasad Sah, G., Bahadur Basnet, B., Raj Bhatt, M., 
Sharma, D., Subedi, K., Pandey, J., \& Malla, R. (2011). Phytochemical extraction and antimicrobial properties of different medicinal plants: Ocimum sanctum (Tulsi), Eugenia caryophyllata (Clove), Achyranthes bidentata (Datiwan) and Azadirachta indica (Neem). Journal of Microbiology and Antimicrobials, 3(1), 1-7.

Kamra, D. N., Patra, A. K., Chatterjee, P. N., Kumar, R., Agarwal, N., \& Chaudhary, L. C. (2008). Effect of plant extracts on methanogenesis and microbial profile of the rumen of buffalo: a brief overview. Australian Journal of Experimental Agriculture, 48(2), 175-178.

Kamruzzaman, M., Torita, A., Sako, Y., Al-Mamun, M., \& Sano, $\mathrm{H}$. (2011). Effects of feeding garlic stem and leaf silage on rates of plasma leucine turnover, whole body protein synthesis and degradation in sheep. Small Ruminant Research, 99(1), 37-43.

Kongmun, P., Wanapat, M., Pakdee, P., \& Navanukraw, C. (2010). Effect of coconut oil and garlic powder on in vitro fermentation using gas production technique. Livestock Science, 127(1), 38-44.

Lambert, R. J. W., Skandamis, P. N., Coote, P. J., \& Nychas, G.J. E. (2001). A study of the minimum inhibitory concentration and mode of action of oregano essential oil, thymol and carvacrol. Journal of Applied Microbiology, 91(3), 453-462.

Lazzarini, I., Detmann, E., Sampaio, C. B., Paulino, M. F., Valadares Filho, S. de C., Souza, M. A. de, \& Oliveira, F. A. (2009). Intake and digestibility in cattle fed low-quality tropical forage and supplemented with nitrogenous compounds. Revista Brasileira de Zootecnia, 38(10), 2021-2030.

Lee, H. S., Koo, Y. C., Suh, H. J., Kim, K. Y., \& Lee, K. W. (2010). Preventive effects of chebulic acid isolated from Terminalia chebula on advanced glycation endproduct-induced endothelial cell dysfunction. Journal of Ethnopharmacology, 131(3), 567-574.

Ngamsaeng, A., Wanapat, M., \& Khampa, S. (2006). Effects of Mangosteen peel (Garcinia mangostana) supplementation on rumen ecology, microbial protein synthesis, digestibility and voluntary feed intake in cattle. Pakistan Journal of Nutrition, 5(5), 445-452.

Pal, D. C., \& Jain, S. K. (1989). Notes on Lodha medicine in Midnapur District, West Bengal, India. Economic Botany, 43(4), 464-470.

Partanen, K. H., \& Mroz, Z. (1999). Organic acids for performance enhancement in pig diets. Nutrition Research Reviews, 12, 117-145.

Patra, A. K., \& Saxena, J. (2009). Dietary phytochemicals as rumen modifiers: A review of the effects on microbial populations. Antonie van Leeuwenhoek, International Journal of General and Molecular Microbiology, 96(4), 363-375.

Rota, C., Carramiñana, J. J., Burillo, J., \& Herrera, A. (2004). In vitro antimicrobial activity of essential oils from aromatic plants against selected foodborne pathogens. Journal of Food Protection, 67(6), 1252-1256.

Roth, F. X., \& Kirchgessner, M. (1998). Organic acids as feed additives for young pigs: Nutritional and gastrointestinal effects. Journal of Animal and Feed Sciences, 7(Suppl. 1), 25-33.

Saleem, A., Husheem, M., Härkönen, P., \& Pihlaja, K. (2002). Inhibition of cancer cell growth by crude extract and the phenolics of Terminalia chebula Retz. fruit. Journal of Ethnopharmacology, 81(3), 327-336.

SAS (2003). Statistical Analysis System, Version 9.1, SAS Institute, Cary, NC, USA.
Sato, Y., Oketani, H., Singyouchi, K., Ohtsubo, T., Kihara, M., Shibata, H., \& Higuti, T. (1997). Extraction and purification of effective antimicrobial constituents of Terminalia chebula Retz. against methicillin-resistant Staphylococcus aureus. Biological and Pharmaceutical Bulletin, 20(4), 401-404.

Saxena, M., Saxena, J., Nema, R., Singh, D., \& Gupta, A. (2013). Phytochemistry of medicinal plants. Journal of Pharmacognosy and Phytochemistry, 1(6), 168-182.

Sehm, J., Lindermayer, H., Dummer, C., Treutter, D., \& Pfaffl, M. W. (2007). The influence of polyphenol rich apple pomace or red-wine pomace diet on the gut morphology in weaning piglets. Journal of Animal Physiology and Animal Nutrition, 91(7-8), 289-296.

Sultana, N., Huque, K. S., \& Alimon, A. R. (2012). Effect of Sapindus mukorossi as herbal feed additive for ruminants. Malaysia Journal of Animal Science, 15, 37-44.

Tekeli, A., Çelik, L., \& Kutlu, H. R. (2007). Plant extracts: A new rumen moderator in ruminant diets. Journal of Tekirdag Agricultural Faculty, 4(1), 71-79.

Tewari, D., Mocan, A., Parvanov, E. D., Sah, A. N., Nabavi, S. M., Huminiecki, L., Ma, Z. F., Lee, Y. Y., Horbańczuk, J. O., \& Atanasov, A. G. (2017). Ethnopharmacological approaches for therapy of jaundice: Part II. Highly used plant species from Acanthaceae, Euphorbiaceae, Asteraceae, Combretaceae, and Fabaceae families. Frontiers in Pharmacology, 8, Article 519.

Valenzuela-Grijalva, N. V., Pinelli-Saavedra, A., MuhliaAlmazan, A., Domínguez-Díaz, D., \& González-Ríos, H. (2017). Dietary inclusion effects of phytochemicals as growth promoters in animal production. Journal of Animal Science and Technology, 59, Article number 8.

Vergis, J., Gokulakrishnan, P., Agarwal, R. K., \& Kumar, A. (2015). Essential Oils as Natural Food Antimicrobial Agents: A Review. Critical Reviews in Food Science and Nutrition, 55(10), 1320-1323.

Wanapat, M., Kang, S., Khejornsart, P., \& Wanapat, S. (2013). Effects of plant herb combination supplementation on rumen fermentation and nutrient digestibility in beef cattle. AsianAustralasian Journal of Animal Sciences, 26(8), 1127-1136.

Wanapat, M., Khejornsart, P., Pakdee, P., \& Wanapat, S. (2008). Effect of supplementation of garlic powder on rumen ecology and digestibility of nutrients in ruminants. Journal of the Science of Food and Agriculture, 88(13), 2231-2237.

Wang, J. P., Yoo, J. S., Jang, H. D., Lee, J. H., Cho, J. H., \& Kim, I. H. (2011). Effect of dietary fermented garlic by Weissella koreensis powder on growth performance, blood characteristics, and immune response of growing pigs challenged with Escherichia coli lipopolysaccharide. Journal of Animal Science, 89(7), 2123-2131.

Windisch, W., Schedle, K., Plitzner, C., \& Kroismayr, A. (2008a). Use of phytogenic products as feed additives for swine and poultry. Journal of Animal Science, 86(14), E140-E148.

Windisch, W., Schedle, K., Plitzner, C., \& Kroismayr, A. (2008b). Use of phytogenic products as feed additives for swine and poultry. Journal of Animal Science, 86(14), E140-E148.

Zhang, S., Jung, J. H., Kim, H. S., Kim, B. Y., \& Kim, I. H. (2012). Influences of phytoncide supplementation on growth performance, nutrient digestibility, blood profiles, diarrhea scores and fecal microflora shedding in weaning pigs. AsianAustralasian Journal of Animal Sciences, 25(9), 1309-1315. 